\title{
LIDAR\&RADIOMETER INVERSION CODE (LIRIC) FOR SYNERGETIC PROCESSING OF EARLINET, AERONET AND CALIPSO LIDAR DATA
}

\section{Anatoli Chaikovsky*, Ludmila Chaikovskaya, Natalia Denishchik-Nelubina, Anton Fedarenka, Sergey Oshchepkov}

${ }^{I}$ Institute of Physics, National Academy of Sciences, Belarus, *chaikovl@dragon.bas-net.by

\begin{abstract}
Lidar\&Radiometer Sounding (LRS) technique is used to obtain the "snapshot" of aerosol concentration profiles over the East European region during dust event, 07-08.04.2016 from EARLINET, AERONET and CALIPSO data. Aerosol concentration profiles retrieved from space and ground-based lidars are compared.
\end{abstract}

\section{INTRODUCTION}

In the recent years, combined lidar and radiometer sounding (LRS) technique becomes one of the basic tools in comprehensive investigations of the atmosphere aimed at retrieving altitude distributions of aerosol optical parameters and aerosol mode concentrations of an inhomogeneous aerosol layer [1,2].

However, the insufficient number of coincident lidar and sun-radiometer stations restrict employment of LRS technique for monitoring atmospheric aerosol. Nowadays, more than 400 active AERONET sun-radiometer stations provide regular observations in the different geophysical regions. At the same time, the number of lidar systems with required technical characteristics for providing LRS measurements and collocated with AERONET sun-radiometer systems is an order of magnitude smaller. Furthermore, the number of combined lidar and radiometer stations is expected not to be increased significantly in the near future.

Using data, measured by satellite multiwavelength lidars, like the CALIOP, working in the vicinity of AERONET station, for retrieving aerosol parameters becomes a real possibility to widen the LRS-area of applications. The most promise variant of complex LRS-experiment is carrying out coincident ground-based and satellite multiwavelength lidar measurements and AERONET observations.
This paper presents the results of development of the algorithm and software package for retrieval of aerosol mode concentration profiles from CALIPSO and AERONET data.

\section{SET UP FOR THE PROBLEM}

Initially algorithm and software LIRIC [1] were developed for the processing data of combined groundbased lidar and radiometer measurements. We assume that lidar provides measurements of backscatter signal at three wavelengths $(355,532$ and $1064 \mathrm{~nm})$ or at two wavelengths with both cross- and parallel polarization components of the lidar signal for a third wavelength.

The aerosol model is formed as a mixture of $k=1, . ., K$ aerosol modes which consists of spherical and spheroid particles with volume size distributions, $d \mathrm{~V}_{k}(r) / d \ln r$, and refractive index $n$ that are the same for all particles. The part of spherical particles in the aerosol mixture ("sphericity") doesn't depend on particle sizes.

The aerosol layer is defined with two sets of parameters:

a) integral parameters characterizing the aerosol layer as a whole: size distributions of aerosol modes, their total content (column concentrations), refractive index and "sphericity";

b) concentrations, $c_{k}(h)$, of aerosol modes changing over altitude.

Aerosol particle size distribution are characterized by two fractions (fine and coarse) with bounding radius of $\sim 0.5$ micrometers, as it is the convention in AERONET retrievals. Particle size distribution of each fraction and refractive index is considered to be independent of the altitude.

Spherical and non-spherical particles of the coarse mode are considered as two different fractions if measurements of couple of cross/parallel polarization components are available.

CALIOP provides measurements of lidar signal at two wavelengths (532 and $1064 \mathrm{~nm}$ ) and intensity 
of the cross polarization signal component at wavelength of $532 \mathrm{~nm}$. We have shown in [1] that retrieved concentration profiles, $c_{k}(h)$, for two-, and three aerosol models, after elimination of the 355-lidar signal from the input data set undergo insignificant changes. Thus, the CALIOP data are expected to be sufficient to retrieve aerosol parameters by means of LRS algorithm and LIRIC program package.

Geometry of the combined ground-based radiometer and space lidar experiment are different from that for two ground-based systems. These differences are taken into account in the algorithm.

\section{ALGORITHM}

For the data processing of combined AERONET/CALIPSO experiments we transform lidar signals measured by CALIOP at the level $h_{\infty}$ into signals of virtual system "Lidar-V" at the ground level $h_{0}$ (Fig. 1).

Range-corrected CALIOP lidar signals, $S_{C, j}^{*}\left(R_{i}\right)=\mathrm{P}_{C, j}^{*}\left(\lambda_{j}, R_{i}\right) R_{i}^{2}$, can be written by the following equation [3]:

$$
\begin{aligned}
& S_{C, j}^{*}\left(R_{i}\right)=E_{C, j} \xi_{C, j} \beta_{j}\left(\lambda_{j}, R_{i}\right) T_{j}^{2}\left(\lambda_{j}, R_{i}\right) \\
& =E_{C, j} \xi_{C, j} \beta_{j}\left(\lambda_{j}, R_{i}\right) \frac{T_{j}^{2}\left(\lambda_{j}, R_{h_{0}}\right)}{T_{j}^{2}\left(\lambda_{j}, h_{i}\right)}
\end{aligned}
$$

where $j$ is the number of receiving channel; $R_{i}$ is the range from the satellite to the sampled volume; $\mathrm{P}_{C, j}^{*}\left(R_{i}\right)$ is the CALIOP measured signal at the wavelength $\lambda_{j}$ after background subtraction and artifact removal; $E_{C, j}$ is the average CALIOP laser energy; $\xi_{C, j}$ is the CALIOP system parameter; $\beta_{j}\left(\lambda_{j}, R_{i}\right)$ is the backscatter coefficient at the range $R_{i}$; $T_{j}\left(\lambda_{j}, R_{i}\right)$ is transmittance from CALIOP, level, $h_{\infty}$, to the scattering volume at the range $R_{i}$.

A range corrected signal of the virtual lidar,

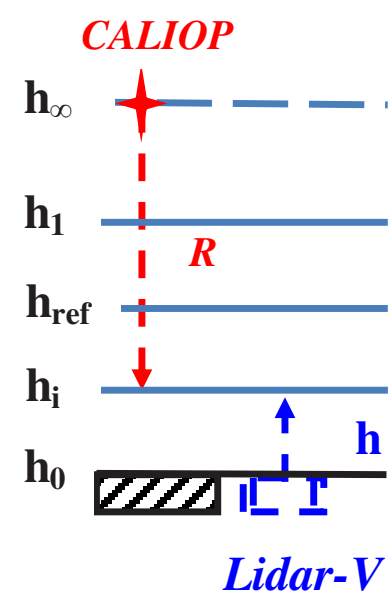

Figure 1 The scheme of lidar measurements

$S_{V, j}^{*}\left(h_{i}\right)=\mathrm{P}_{V, j}^{*}\left(\lambda_{j}, h_{i}\right) h_{i}^{2}$ can be written in the same manner:

$$
S_{V, j}^{*}\left(h_{i}\right)=E_{V, j} \xi_{V, j} \beta_{j}\left(\lambda_{j}, h_{i}\right) T_{j}^{2}\left(\lambda_{j}, h_{i}\right) .
$$

Using Eq. (1) and Eq. (2) the relation between $S_{V, j}^{*}\left(h_{i}\right)$ and $S_{C, j}^{*}\left(R_{i}\right)$ can be defined as follows:

$$
S_{V, j}^{*}\left(h_{i}\right)=\frac{E_{V, j} \xi_{V, j} S_{C, j}^{*}\left(h_{i}\right) T_{j}^{4}\left(\lambda_{j}, h_{i}\right)}{E_{C, j} \xi_{C, j} T_{j}^{2}\left(\lambda_{j}, R_{h_{0}}\right)} .
$$

Given Eq. (3) the relation between the measured $\mathbf{L}^{*}$ and aerosol mode concentration, $\mathrm{c}_{k}(h)$, can be expressed by the vector equation:

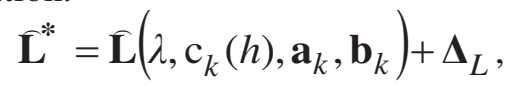

In this equation the components of $\mathbf{L}^{*}$ are defined as follows:

$$
\widehat{L}_{V, j}^{*}\left(h_{i}\right)=\frac{S_{C, j}^{*}\left(h_{i}\right)}{S_{C, j}^{*}\left(h_{r e f}\right)} \exp \left(2 \delta_{h, h_{r e f}} \tau_{r, j}\left(h_{i}, h_{r e f}\right)\right)
$$

$\delta\left(h, h_{\text {ref }}\right)$ is the utility function:

$$
\delta_{h_{i}, h_{r e f}}=\left\{\begin{array}{cll}
1 & \text { if } & h_{i} \leq h_{r e f} \\
-1 & \text { if } & h_{i}>h_{\text {ref }}
\end{array} .\right.
$$


Modeled lidar function $\mathrm{L}_{V, j}(\ldots)$ can be written in the following:

$$
\widehat{L}_{V, j}\left(h_{i}\right)=\frac{\beta_{j}\left(h_{i}\right) \exp \left(-2 \delta_{h, h_{r e f}} \tau_{a, j}\left(h_{i}, h_{r e f}\right)\right)}{\beta_{r, j}\left(h_{r e f}\right) \hat{\mathrm{R}}_{j}\left(\lambda_{j}, h_{r e f}\right)}
$$

$\tau_{r, j}\left(\lambda_{j}, h_{i}, h_{r e f}\right)$ is the molecular optical thickness related to the range of $\left(h, h_{r e f}\right)$; $\tau_{a, j}\left(\lambda_{j}, h_{i}, h_{r e f}\right)$ is the aerosol optical thickness; $\Delta_{L}$ is the vector of measurement uncertainties.

Equations (4)-(7) determine procedure of the lidar data processing for retrieving aerosol parameters from combined AERONET/CALIOP data. The basic difference between Eqs. (4) - (7) and appropriate equations for processing data of two ground-based systems is opposite sign in the exponential rate of eq. (5) and (7). This feature provides easy correction of the software LIRIC for the data processing combined AERONET/CALIOP.

\section{CASE STUDY OF COINCEDENT EARLINET, AERONET AND CALIPSO DATA PROCESSING}

Data of coincident EARLINET, AERONET and CALIPSO measurements in the East European region during Saharan dust events, 07-08.04.2016 were used to test LRS technique and software for retrieving aerosol parameters from ground-based radiometer and satellite lidar systems.

The map of dust optical thickness, AERONET stations and CALIPSO trajectories are shown in figure 2. The AERONET active systems in the East European region which data can be combined with CALIOP data during 07-08.04.2016 were stations in Kyiv, Minsk, Toravere, Ersa (07.04.2016) and Athens-NOA (08.04.2016). Simultaneously, the EARLINET station in Minsk provided ground-based lidar observations.

The results of the EARLINET, AERONET and CALIPSO data processing are presented in Fig. 4 and Fig. 5. Retrieved profiles of the aerosol mode concentration correspond to the forecast of the dust spatial distribution.

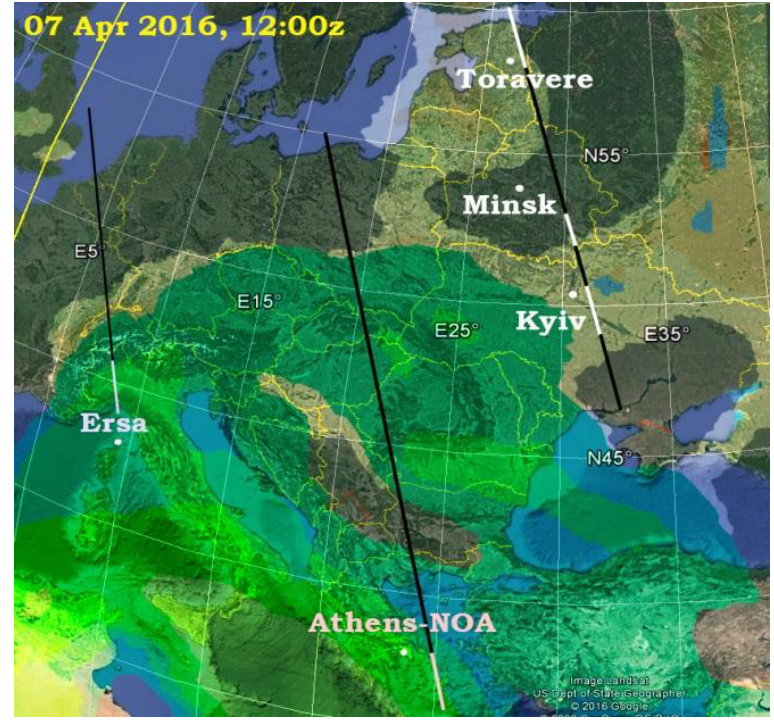

Figure 2 The map of dust optical thickness, (0704-2016, NAAPS), ground-based stations and CALIPSO trajectories

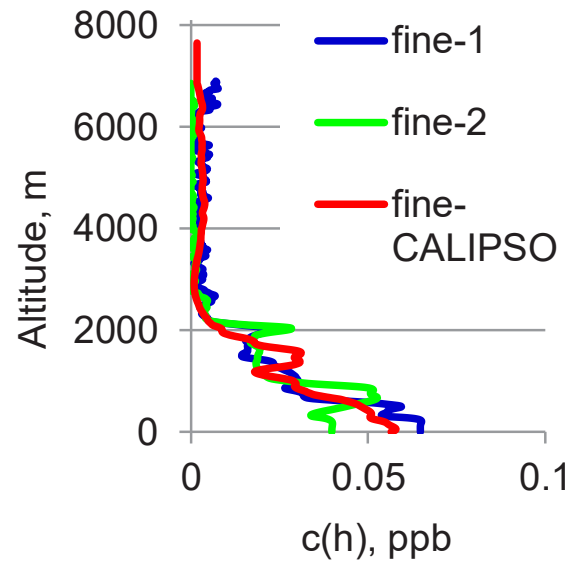

a)

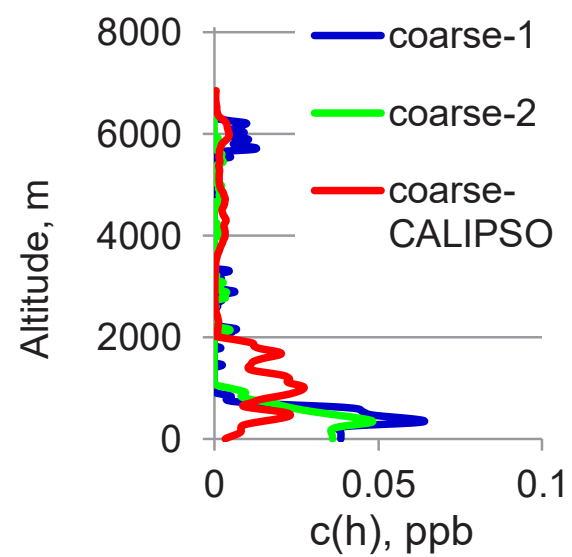

b)

Figure 3 Profiles of aerosol fine (a) and coarse (b) mode concentrations, Minsk, 07-04-2-16; 1 ground-based lidar, 09:17:30; 2 -ground-based lidar, 10:11:46; CALIPSO, 11:00:47 

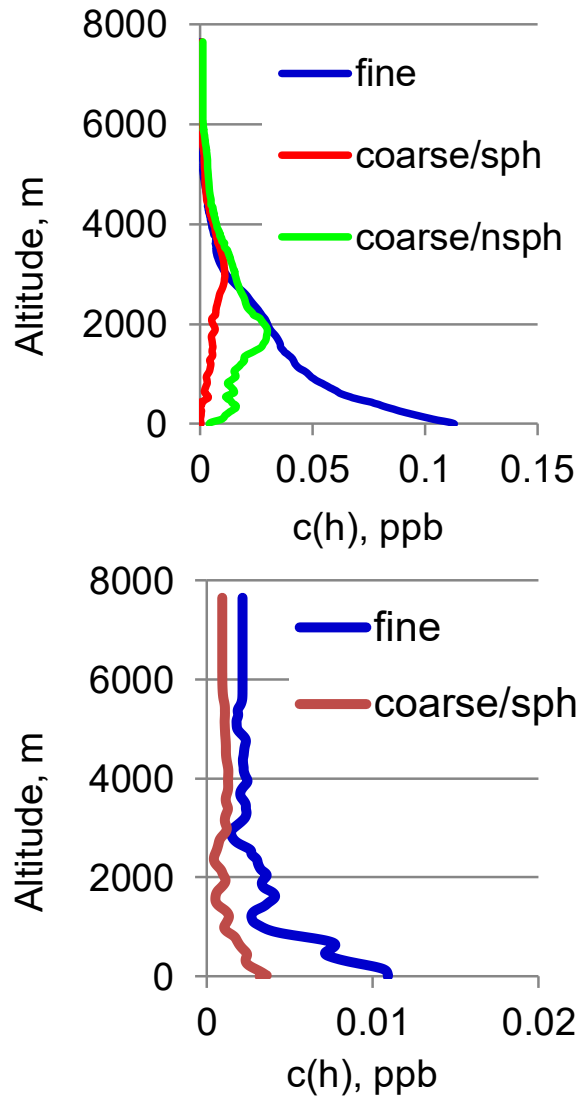

Figure 4 Profiles of aerosol mode concentrations; a) Kyiv (CALIPSO), 07-04-2016; 10:59:37; b) Toravere (CALIPSO), 07-04-2016; 11:02:27

Selected CALIPSO trajectory segment for Minsk site was moved to the South because of cloudy atmosphere in the Minsk region. Nevertheless, profiles of fine aerosol particles retrieved from ground-based lidar are very close to those from CALIOP. Coarse mode of aerosol particles was more variable.

Results of the case study demonstrate realizability of the LRS-technique for retrieving aerosol parameters from combined AERONET/CALIPSO data.

\section{ACKNOWLEDGEMENTS}

The financial support by the European Union's Horizon 2020 research and innovation programme (ACTRIS-2, grant agreement no. 654109) is gratefully acknowledged. The investigation was supported by the Belarusian Republican Foundation for Fundamental, Research Agreement No. F15SB-023. We acknowledge the AERONET community, Atmospheric Science
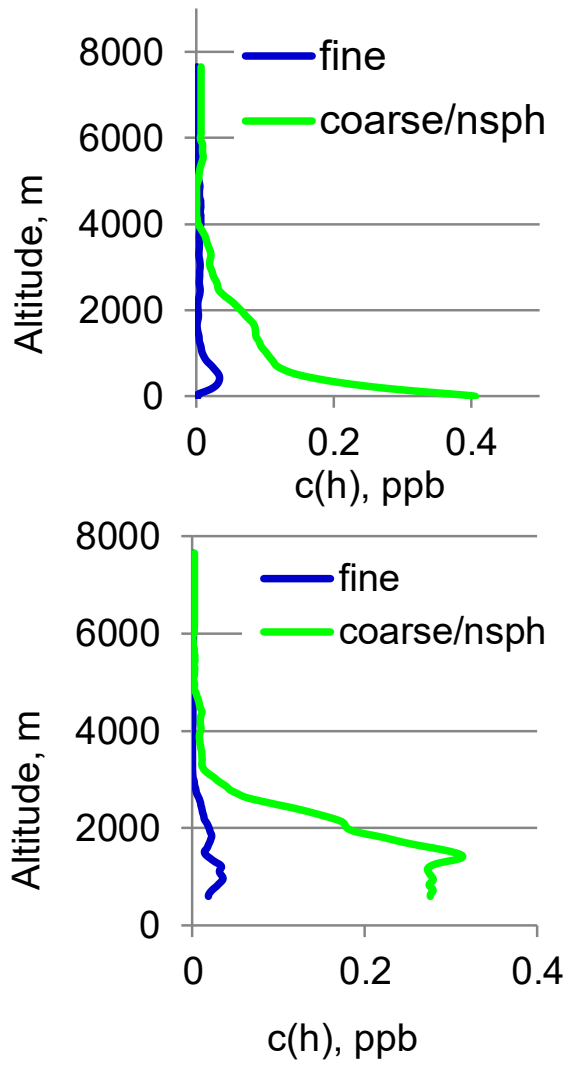

Figure 4 Profiles of aerosol mode concentrations; a) Ersa (CALIPSO), 07-04-2016; 12:13:16; b) Athens-NOA (CALIPSO), 08-04-2016; 11:39:19

Data Center and the Naval Research Laboratory for the provision of the radiometer and CALIPSO data and NAAPS information.

\section{References}

[1] Chaikovsky, A., et al., 2016: Lidar-Radiometer Inversion Code (LIRIC) for the retrieval of vertical aerosol properties from combined lidar/radiometer data: development and distribution in EARLINET, Atmos. Meas. Tech., 9(3), 1181-1205.

[2] Lopatin, A., et al., 2013: Enhancement of aerosol characterization using synergy of lidar and sun - photometer coincident observations: the GARRLiC algorithm, Atmos. Meas. Tech. 6, 2065-2088.

[3] CALIOP Algorithm Theoretical Basis Document; Calibration and Level 1 Data Products. PC-SCI-201, Release 1.0, 7 April 2006, 66 ph. 